\title{
CrimRxiv
}

\section{The Role of Community-}

Mindedness in the SelfRegulation of Drug

Cultures: A Case Study

from the Shetland Islands

\section{Anke Stallwitz}

Published on: Jan 01, 2012

License: Creative Commons Attribution 4.0 International License (CC-BY 4.0). 
